\title{
EDITORIAL ADDENDUM
}

\section{Nanocasting nanoporous inorganic and organic materials from polymeric bicontinuous microemulsion templates}

\author{
Brad $\mathrm{H}$ Jones and Timothy P Lodge
}

Polymer Journal (2012) 44, 370; doi:10.1038/pj.2012.8

Correction to: Polymer Journal (2012) 44, 131-146; doi:10.1038/pj.2011.136

During 2012, the year of the Society of Polymer Science, Japan (SPSJ)'s 60th anniversary, Polymer Journal is planning to publish a series of invited review articles specially solicited from internationally renowned polymer scientists and past recipients of the SPSJ International Award. The first article is by Professor Tim Lodge of the University of Minnesota which was published in the February issue.
We are sorry that his biography was missing from the article, and would like to hereby publish it.

Once again, we appreciate Professor Lodge's kind contribution to Polymer Journal.

Polymer Journal Editorial Office

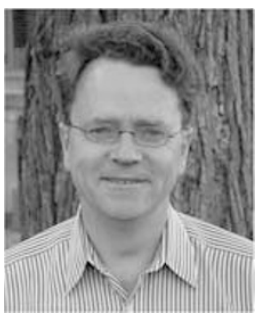

Tim Lodge graduated from Harvard in 1975 with a BA cum laude in Applied Mathematics, and in 1980 he earned his PhD in Chemistry at the University of Wisconsin, working with Professor John Schrag. Tim spent 20 months as a National Research Council Postdoctoral Fellow at NIST, collaborating with Dr Charles Han. Since 1982 he has been on the Chemistry faculty at the University of Minnesota, and in 1995 he also became a Professor of Chemical Engineering \& Materials Science. Since 2001 he has been the Editor of the ACS journal Macromolecules. He has authored or co-authored over 300 papers in the field of polymer science, and advised or coadvised over $50 \mathrm{PhD}$ students. His research interests center on the structure and dynamics of polymer liquids, including solutions, melts, blends and copolymers, with particular emphases on rheology, diffusion, scattering and microscopy techniques. 